\title{
LOS ITINERARIOS DE LA CONQUISTA: EL RELATO DE ‘ARĪB
}

\author{
Luis Molina \\ C.S.I.C., Granada
}

En un trabajo reciente ${ }^{1}$ analizábamos una de las distintas versiones que sobre la conquista musulmana de la Península Ibérica nos han transmitido los cronistas árabes. El texto objeto de estudio en aquella ocasión era, según creemos haber demostrado en ese artículo, el salido de la pluma de Aḥmad al-Rāzī; bien fuera por su prestigio como historiador, bien porque su relato fuera considerado el más fiable por los autores posteriores, lo cierto es que su versión fue, con diferencia, la más difundida, no sólo entre los historiadores árabes, sino también entre los cronistas medievales hispánicos. Mucho menor éxito fue el conseguido por la versión que vamos a estudiar ahora, si bien su influencia en la historiografía referida a alAndalus fue, si no intensa, sí duradera, ya que, como inmediatamente comprobaremos, pueden hallarse huellas nítidas incluso en textos de finales del siglo XVII.

Según el relato que atribuíamos a Ạ̣mad al-Rāzī, el itinerario de Țāriq, tras la victoria sobre Rodrigo, se inicia en Écija, donde, tras conquistar la plaza, divide su ejército, siguiendo los consejos de Julián, en cuatro destacamentos: uno se dirige a Córdoba, otro, a Málaga/Rayya, el tercero a Elvira y el último, comandado por el propio Țāriq, a Toledo.

Las tropas enviadas a Rayya y Elvira, conseguidos sus objetivos en esas regiones, se reúnen y se encaminan hacia Orihuela, que pasa a manos musulmanas tras pactar con el señor de la ciudad, el célebre Teodomiro/Tudmīr.

El grueso de ese contingente se reúne con Târiq en Toledo. En una localidad cercana a la capital de los godos, Țāriq se apodera de la "Mesa" de Salomón, a la que arranca una de sus patas.

Mientras tanto, Mūsà, enterado de los éxitos de su lugarteniente, y envidioso de ellos, pasa a al-Andalus, desembarcando en Algeciras. Allí decide no seguir el mismo camino de Țāriq y sus aliados cristianos le proponen un itinerario que pasa por ciudades que no habían sido conquistadas todavía. De este modo, tras apoderarse de Sidonia, Carmona y Sevilla, llega a Mérida, que resiste duramente, aunque al final acaba pactando su entrega. Mientras tanto, los sevillanos se habían rebelado contra los invasores y habían dado muerte, ayudados por sus correligionarios de Beja y Niebla, a una treintena de musulmanes. Avisado de ello por los supervivientes que habían conseguido huir, Mūsà envía a su hijo 'Abd al'Azīz, que reconquista la plaza y castiga a sus habitantes.

${ }^{1}$ «Un relato de la conquista de al-Andalus», Al-Qantara XIX (1998), 39-65. 
Mūsà se reúne con Țāriq en Toledo e, irritado con él, lo humilla en público. Tāariq le entrega la "Mesa» de Salomón y juntos marchan a conquistar Zaragoza. Finalmente, el califa envía a un emisario que hace que Mūsà y Țāriq regresen a Oriente.

La versión que vamos a estudiar a continuación coincide en líneas generales con la de al-Rāzì, aunque difiere de forma clara en los detalles del recorrido seguido por los conquistadores. Hallamos de nuevo a Julián como figura instigadora y colaboradora, a Ṭāriq cruzando el Estrecho con su ayuda, derrotando en el Guadalete al rey Rodrigo y progresando victoriosamente hasta Toledo, y a Mũsà, celoso del éxito de su lugarteniente, pasando a al-Andalus para, siguiendo un camino distinto, encontrarse con Taāriq en Toledo.

Pero junto a estas evidentes semejanzas, las divergencias entre ambos relatos son lo suficientemente notorias para permitirnos identificar sin lugar a dudas qué crónicas sigue esta versión y diferenciar con precisión, dentro de esas crónicas, los pasajes que derivan de ella y los tomados de otras fuentes.

Aunque son varias las obras sobre las que este relato de la conquista ha ejercido influencia, únicamente tres son las que lo reproducen íntegra o ampliamente: el Kitāb Șilat al-simt ${ }^{2}$, de Ibn al-Šabbāt (618-681/1221-1282), el anónimo Fath al-Andalus ${ }^{3}$ y la Riḥlat al-Wazīr de al-Gassānī (m. 1119/1707) ${ }^{4}$. Las relaciones entre estos dos últimos textos son bien conocidas desde antiguo y parece seguro que su parentesco proviene del hecho de que ambos derivan de una fuente común ${ }^{5}$. En el análisis que emprendemos a continuación hallaremos nuevos indicios que confirmarán o refutarán esa hipótesis, al tiempo que intentaremos establecer el tipo de relación de la obra de Ibn al-Šabbāt con el Fatḥ y la Riḥla (y con su hipotética fuente común) y averiguar el origen último del texto, es decir, identificar al autor de esta versión de la conquista.

Como se ha comentado antes, las diferencias más importantes entre la narración de Aḥmad al-Rāzī y la que ahora estudiamos se hallan en el itinerario seguido por Taāiq tras su victoria sobre Rodrigo y en el de Mūsà cuando pasó a la Península al año siguiente. La ruta tomada por Tāāiq, según este relato, lo llevó desde Sidonia hasta Toledo, pasando por Morón, Carmona, Sevilla, Écija y Córdoba, mientras que Mūsà, tras desembarcar en Algeciras, elige un camino más al occidente, que lo conduce por Niebla, Beja y Mérida.

\footnotetext{
${ }^{2}$ Ta'nj̄ al-Andalus li-bn al-Kardabūs wa-wasfu-hu li-bn al-Šabbät. Nassāni ŷad ìdāni, ed. A. M. al-'Abbādī, Madrid, 1971; el texto de Ibn al-Šabbặt ocupa las páginas 127 a 191.

${ }^{3}$ Fath al-Andalus (La conquista de al-Andalus), ed. L. Molina, Madrid, 1994.

${ }^{4}$ Rih̨lat al-wazìr fì ftikäk al-asīr, ed. A. al-Bustānī, Tánger, 1940; v. Lévi-Provençal, E., Les Historiens des Chorfa, Paris, 1922, 284-286. Sobre la embajada de al-Gassānī, v. Arribas Palau, M., "De nuevo sobre la embajada de al-Gassānī”, Al-Qantara VI (1985), 199-289.

${ }^{5}$ Fath al-Andalus, XXIII-XXIX.
} 
El texto de Ibn al-Šabbăt fue estudiado y traducido hace algunos años por Emilio de Santiago ${ }^{6}$, quien ya puso de relieve las semejanzas que presentaba el texto por él traducido con los del Fath y la Rihla. La causa de ese parentesco era, para él, que todas estas obras derivaban de la de Aḥmad al-Rāzī, quien, a su vez, sería deudor de 'Abd al-Malik b. Habib7. Si tenemos en cuenta lo ya señalado antes en el sentido de que la versión de al-Rāzī es muy parecida a la nuestra en la estructura general y que sólo se aparta de ella en los detalles, tal vez podría pensarse que los tres textos emparentados entre sí, Sila, Fath y Rihla, derivan de una fuente común que se basa en al-Rāzī pero que introduce esas modificaciones menores que distinguen claramente a esta familia de textos de las obras más fieles al modelo del historiador cordobés. Creemos que no es así, sino que nos encontramos ante una versión independiente de la que incluyó en su crónica al-Rāzī, lo cual no quiere decir que las informaciones proporcionadas por éste no pudieran haber sido aprovechadas por nuestro autor para elaborar su texto, sino que la redacción del mismo fue obra personal suya y no copia más o menos alterada de una fuente anterior.

El primer paso a dar será, por tanto, intentar descubrir la personalidad del autor originario. Para ello nos basaremos en el testimonio de Ibn al-Šabbăt, autor que, como bien señaló ya De Santiago ${ }^{8}$, tiene un especial cuidado en precisar la fuente de donde toma cada pasaje. El hecho de que, en ocasiones, las citas que él reproduce contengan, a su vez, citas de otros autores, puede hacer un poco complicada la labor, pero, si se analiza con cuidado y minuciosidad, se comprueba que es perfectamente posible determinar dónde comienza y dónde termina cada cita; gracias a ello, no nos será difícil indagar de dónde proceden los párrafos de esta versión de la conquista que son reproducidos por Ibn al-Šabbāt.

La descripción de al-Andalus de Ibn al-Šabbặt comienza con la fijación de sus límites geográficos (p. 127-128; citas del Kitäb Nuzhat al-nufüs y del Kitäb al$M u^{\prime}$ 'rib), el origen de su nombre (p. 128; cita de Ibn Abī 1-Fayyāạ), una breve descripción general (p. 129-131; citas de al-Bakrīi, Ibn al-Jarrāt —que cita a alRāzi- y Șā̄id ${ }^{9}$ ) y un párrafo sobre los primeros pobladores (p. 132; tomado de Ibn al-Jarrāt $\left.{ }^{10}\right)$.

${ }^{6}$ "Los itinerarios de la conquista musulmana de al-Andalus a la luz de una nueva fuente: Ibn alŠabbăț, Cuadernos de Historia del Islam 3 (1971), 51-65 y «Un fragmento de la obra de Ibn al-Šabbāt (s. XIII) sobre al-Andalus", Cuadernos de Historia del Islam 5 (1973), 5-91.

7 "Los itinerarios", 62. La supuesta utilización de al-Rāzĩ por parte de Ibn al-Šabbāt tampoco sería directa para Emilio de Santiago, ya que lo cree einspirado en el compendio de la obra de al-Rušătī que Ibn al-Jarrăt realizara" (56). Más adelante veremos que el Ijtișär Iqtibäs al-anwär no es la fuente de las noticias históricas que Ibn al-Šabbāt reproduce.

${ }^{8}$ "Los itinerarios", 52, n. 8.

${ }^{9}$ Es muy probable que, al igual que al-Rāzī, también Șā̄id sea citado de forma indirecta, a través de Ibn al-Jarrăt.t. El mismo pasaje, con la mezcla de al-Rāzī y Șā‘id, lo hallamos resumido en el Rawd de al-Ḩimyarī (ed. Lévi-Provençal, La Péninsule Ibérique au Moyen-Âge, Leiden, 1938, 1).

${ }^{10}$ No lo cita expresamente, pero en una de las notas con las que Ibn al-Šabbăt comenta el texto (165, «Ṭūbāl») señala que ésa es la versión del Ijtișār Iqtibās al-anwār. 
A continuación comienza el relato de la conquista con una cita del ljtișār de Ibn al-Jarrāt (p. 131), que resume todos los acontecimientos en unas pocas líneas; a esto le sigue la legendaria historia de la "Casa cerrada" de Toledo, según las versiones de Ibn al-Kardabūs (p. 131-132) y de Ibn Abī l-Fayyāọ (p. 132) y un par de narraciones no menos legendarias: el hallazgo de unas estatuas con ropajes árabes en una cámara subterránea, anuncio inequívoco de la invasión (del Kitāb al-Mu 'rib; pp. 132-133) y la anciana que había descrito con todo detalle los rasgos físicos del conquistador, rasgos que coincidían con los de Țāriq (Ibn Abī 1-Fayyāị:; p. 133).

A partir de aquí comienza la historia seria y detallada con una muy extensa cita del Mujtașar Ta'rīj al-Tabarī, es decir, la crónica de 'Arīb b. Sa 'īd (pp. 133135), donde se nos relata el odio de Julián, gobernador de Tánger, hacia su rey, Rodrigo, que lo lleva a convencer a Țāriq de que pase a al-Andalus. La travesía del Estrecho de los doce mil beréberes de Tãaiq se lleva a cabo en barcos proporcionados por el propio Julián. Rodrigo se dirige desde Córdoba con sus tropas, encontrándose en el Guadalete con los musulmanes. Los flancos del ejército godo estaban mandados por dos hijos del anterior rey, que piensan que, si Rodrigo es derrotado, el trono puede pasar a sus manos, por lo que se conjuran para provocar su ruina. Entablado el combate, tras ocho días de feroz lucha los cristianos son derrotados y se produce una gran carnicería, en la que mueren incluso los dos traidores. El rey Rodrigo huye hacia un lugar llamado Las Acequias (al-Sawāqi) y desaparece, sin que se sepa si murió en combate o ahogado al cruzar el río; sólo se encuentra uno de sus botines ricamente enjoyado. La categoría de los cristianos muertos se conocía por el metal del que estaban hechos sus anillos: oro, plata o cobre. La batalla finalizó el domingo, siete de šawwäl, que se corresponde con el segundo día de tišriñ al-awwal (octubre) ${ }^{11}$ y en ella se obtuvo un botín enorme, que fue repartido entre los supervivientes del ejército musulmán tras haber detraído el quinto legal. A continuación, Ṭāriq se encaminó hacia Sidonia.

En este punto se inicia una serie de apartados con una estructura idéntica: cada uno de ellos está dedicado a una de las ciudades conquistadas por Țāriq y, posteriormente, por Mūsà y comprende una descripción geográfica de la ciudad o de la provincia, la biografía de algún sabio destacado de la localidad (únicamente falta en el caso de Mérida $^{12}$ ) y un párrafo, por lo general breve, sobre su conquista por las tropas musulmanas.

Las localidades descritas son: Sidonia, Morón, Carmona, Sevilla, Écija, Córdoba, Niebla, Beja, Mérida, Toledo y Zaragoza. Ahí finaliza esta sección de

\footnotetext{
${ }^{11}$ En realidad el 7 de šawwal del 92 es el 28 de julio del 711, martes.

${ }^{12}$ Falta también en su modelo, el Ijtișār Iqtibās al-anwār (159), aunque sí hallamos biografía de un sabio emeritense en la fuente de éste, el Iqtibās de al-Rušạtī (54-55).
} 
la Silat al-simt, que continúa con un largo capítulo tomado literalmente del Kitāb al-Imāma wa-l-siyāsa.

Con alguna excepción que inmediatamente comentaremos, la fuente citada continuamente a lo largo del pasaje es el Ijtișär Iqtibās al-anwär del sevillano Ibn al-Jarrāt (510-581/1116-1187), resumen, como su título indica, del Iqtibās alanwār del oriolano al-Rušạtī (466-542/1074-1147) ${ }^{13}$. Esto podría hacernos pensar que Ibn al-Jarrāt es también el autor o el transmisor del relato de la conquista que se halla incluido en este capítulo y que, con no muchas modificaciones, hallamos en el Fath al-Andalus y la Rihlat al-wazìr; gracias a la publicación de los fragmentos conservados de la obra del autor sevillano, sabemos que no es así y, además, disponemos de un elemento de juicio más para valorar la escrupulosidad de la que hace gala en todo momento Ibn al-Šabbāt a la hora de citar a sus fuentes. En efecto, de la confrontación entre los textos de Ibn al-Šabbāt y los de su modelo Ibn al-Jarrāt ${ }^{14}$ se desprenden varias conclusiones:

- La copia es siempre literal, sin la menor alteración. Las únicas diferencias provienen de las contadas ocasiones en las que el tunecino omite alguna frase completa $^{15}$.

- Las descripciones geográficas de las ciudades y las biografías de los varones ilustres locales que las acompañan están tomadas única y exclusivamente del Ijtiṣār Iqtibās al-anwār ${ }^{16}$.

- Ibn al-Šabbāt señala siempre el comienzo de la cita de Ibn al-Jarrāt con la frase "dice en el Ijtișär Iqtibās al-anwän y suele terminarla con las palabras "fin de la descripción" (intahà l-wașf $)^{17}$.

Estamos en condiciones, por tanto, de delimitar con la máxima precisión el comienzo y el fin de todos y cada uno de los préstamos tomados de Ibn al-Jarrāt, de modo que podemos dejarlos de lado y quedarnos con el resto de los pasajes,

\footnotetext{
${ }^{13}$ Al-Andalus fï qtibās al-anwār wa-fïjtișār Iqtibās al-anwār, ed. E. Molina y J. Bosch. Madrid, 1990.

${ }^{14}$ En los fragmentos publicados del Ijtișār Iqtibās al-anwär sólo faltan las descripciones de Écija y Sevilla.

${ }^{15}$ En los casos en los que podemos efectuar una comparación entre las palabras de Ibn al-Šabbạt y las de sus fuentes, por haberse conservado éstas, se demuestra que esa fidelidad a su modelo es una constante a lo largo de toda la Șilat al-simt. El ejemplo más significativo es la copia que hace del Kitab al-Imāma wa-l-siyāsa (Șila, 152-161, Imāma, ed. T. M. al-Zaynī, Beirut. s.a., II, 60-64).

${ }^{16}$ Única excepción: en un caso hallamos una cita de al-Bakrī, en la descripción de Niebla (145). El resto de las citas a otros autores que aparecen en los fragmentos geográficos y biográficos de este capítulo se hallan ya en el ljtișār Iqtibās al-anwār (Ibn al-Faraḍī, 137; Aḥmad al-Rāzī, 139, 146 y 148; al-Zubaydi, 145).

${ }^{17}$ No aparece en los apartados dedicados a Morón, Niebla y Beja, pero sí en los otros ocho.
} 
que forman el relato puramente histórico, el que nos interesa para nuestro propósito.

A lo largo de los pasajes de estos fragmentos históricos son varias las fuentes citadas: Ibn Abī l-Fayyāḍ (p. 144) ${ }^{18}$, 'Arīb y su Mujtașar Ta'rīj al-Ṭabarī (p. 144,

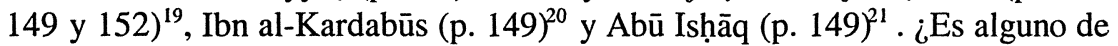
estos cronistas el autor del texto que también reproducen el Fath al-Andalus y la Rihlat al-wazìr? Lo cierto es que sí y que, una vez hemos podido confirmar por otros indicios la personalidad del autor —digámoslo ya, es 'Arīb b. Sa 'īd—, nos damos cuenta de que el propio Ibn al-Šabbạt nos lo estaba diciendo desde el primer momento y que únicamente nuestra falta de confianza en la rigurosidad de Ibn al-Šabbāt al citar sus fuentes nos había impedido apercibirnos de ello.

Poníamos de relieve al comienzo de este trabajo que Ibn al-Šabbāt pone un especial cuidado en indicar en todo momento el origen de las informaciones que reproduce. Pero justamente todos los párrafos del texto que estamos analizando aparecen introducidos por un anónimo «dice» (qäla). En otras obras no es infrecuente hallar numerosos qäla que, por un motivo u otro, acaban siendo simples muletillas que no significan otra cosa que "continúa diciendo el mismo autor». Este podría haber sido el caso de Ibn al-Šabbāt, pero no lo es, porque, como se recordará, estos qăla aparecen justo después de la conclusión de las citas del Ijtișār de Ibn al-Jarrāt y sabemos con certeza, ya que disponemos de extensos fragmentos de ese texto, que este relato de la conquista no procede de su obra ${ }^{22}$. Si el término en cuestión no se refiere a la fuente inmediatamente anterior y si podemos suponer, por el comportamiento habitual de Ibn al-Šabbāt, que no lo ha puesto ahí sin un motivo preciso, es indudable que estos qäla representan efectivamente un cambio de fuente y que dicha fuente no es mencionada explícitamente por alguna razón. ¿Cuál es esa razón? Tal vez pudieran hallarse otras plausibles, pero la correcta, tal y como se demostrará a continuación, es sólo una: todo este relato de la conquista de la Península lo está tomando Ibn al-Šabbāt de una fuente básica y principal, la aludida con esos qăla que, de este modo,

${ }^{18}$ Álvarez de Morales, C., "Aproximación a la figura de Ibn Abī l-Fayyāẹ y su obra histórica", Cuadernos de Historia del Islam 9 (1978-79), 29-127.

${ }^{19}$ Castilla, J., La Crónica de 'Arib sobre al-Andalus, Granada, 1992.

20 'Abbādī, A. M., Ta'rīj al-Andalus li-bn al-Kardabū̄s, 8-14.

${ }^{21}$ Se trata con toda seguridad del kātib Abū Ishāq Ibrāhīm b. al-Qāsim, conocido como al-Raqīq al-Qayrawānī, autor del Ta'rlj Ifriqqiya wa-l-Magrib. Las dos frases en cuestión se hallan en las p. 46 y 50 de la edición de al-Zaydān y Mūsà (Beirut, 1990), en cuya introducción (p. ص) analizan la influencia de al-Raqīq sobre Ibn al-Šabbāt.

${ }^{22}$ Podría argumentarse que estos pasajes se hallaban en la partes perdidas del ljtișār, pero es poco creíble que un diccionario de nisbas como es esa obra, dedicara tanta atención a la descripción de unos acontecimientos históricos. Esto no quiere decir que Ibn al-Jarrāt no mencionara la conquista de la Península por los musulmanes; muy al contrario, podemos afirmar con toda seguridad que lo hacía y, más aún, conocemos exactamente sus palabras: son las que reproduce Ibn al-Šabbạt antes de comenzar con la cita de 'Arīb (p. 131). 
vendrían a significar que se toma de nuevo el curso del relato que forma el hilo conductor, tras haber introducido citas de fuentes secundarias, el Ijtișär de Ibn alJarrāt en varias ocasiones y alguna otra de forma esporádica. Aunque la forma en que ha dispuesto el texto el autor - y suponemos que también influirá algo la mano del editor- hace pensar en un principio que lo importante son las descripciones geográficas de las distintas localidades y que la narración de la conquista es una especie de apéndice menor, lo cierto es que, si nos fijamos bien, comprobaremos que lo que tenemos entre las manos es una crónica de la conquista en la que Ibn al-Šabbạt introduce, después de que el nombre de la localidad tomada por los musulmanes aparezca mencionado en el relato histórico, una descripción geográfica para ilustrar a sus lectores, finalizada la cual vuelve a su fuente, indicándolo con un qäla.

De ser esta suposición cierta - y recurriendo una vez más, a la honradez y al rigor de Ibn al-Šabbāt- deberíamos encontrar en algún lugar de la Șilat al-simt una indicación clara de dónde comienza la cita $-\mathrm{y}$, tal vez, dónde finaliza- $-\mathrm{y}$ cuál es la fuente. Y la verdad es que no nos defrauda: al final del relato, justo antes de que comience otra narración de la conquista tomada del Kitäb al-Imäma wa-l-siyāsa, hallamos la siguiente frase (p. 152): "debes saber que esto es lo que he considerado oportuno incluir de lo que viene en el Mujtasar Ta'rijj al-Tabarī, junto a lo que he añadido tomado de otros autores». En cuanto al inicio, también hallamos una prueba clara - clara, si la contemplamos a la luz de la argumentación que hemos elaborado hasta ahora-: el párrafo anterior a la primera descripción de localidad conquistada, Sidonia, es atribuido expresamente al Mujtașar Ta'rīj al-Tabarī, y dicho párrafo concluye con las palabras «luego avanzó Țāriq hasta caer sobre los habitantes de la ciudad de Sidonia". A continuación, introduce la descripción de Sidonia y la biografía de uno de sus personajes, tomadas ambas de Ibn al-Jarrāt al pie de la letra, y concluye la cita con «acaba la descripción, ¡alabado sea Dios Altísimo!». Sigue inmediatamente Ibn al-Šabbāt con la narración de la conquista de Sidonia, introducida ya por el comentado qāla, que termina con «luego avanzó hacia la cora de Morón», momento en el que, como era de esperar, vuelve a acudir a Ibn al-Jarrāt para ofrecernos las características de Morón. Este esquema se mantiene inmutable a lo largo de todo el capítulo, con las únicas variantes de la inclusión de la ya comentada cita de al-Bakrī en la descripción de Niebla (p. 145), un párrafo sobre la conquista de Córdoba debido a Ibn Abī l-Fayyāḍ (p. 144) y sendas descripciones de la "Mesa" de Salomón procedentes de Ibn al-Kardabūs y Abū Ishạa al-Raqīq (p. 149), que corrigen la decepcionante — para Ibn al-Šabbạtversión de 'Arīb, que sostenía que la fabulosa mesa no era otra cosa que un prosaico atril para los Evangelios.

Nos parece evidente que la narración de la conquista que hallamos en la Silat al-simt procede de la que incluía 'Arīb b. Sa 'īd en su Mujtașar Ta'rīj al-Tabarī; más aún, no sería exagerado asegurar que se trata de una copia muy fiel, casi 
literal, si suponemos que Ibn al-Šabbāt, al seguir a 'Arỉb, utilizó el mismo criterio empleado para copiar a Ibn al-Jarrāt y al Kitāb al-Imāma wa-l-siyāsa, que son los casos en los que podemos confrontar ampliamente su versión con las de sus modelos. De esa confrontación se desprende que, como ya hemos apuntado antes, las palabras que Ibn al-Šabbāt dice tomar de esas dos obras son exactamente las mismas que encontramos en los originales, siendo las únicas diferencias algunas contadas, esporádicas y breves frases que son omitidas intencionada o involuntariamente.

Despojando el pasaje que Ibn al-Šabbật copia a 'Arīb de todas las citas de otros autores, tenemos el texto que presentamos a continuación ${ }^{23}$ :

$$
\begin{aligned}
& \text { قال في مختصر تاريخ الطبري رمه الله: }
\end{aligned}
$$

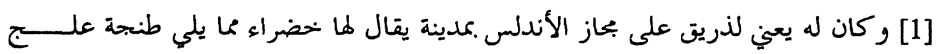

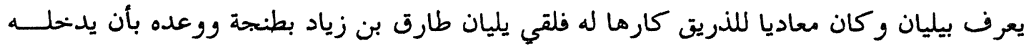

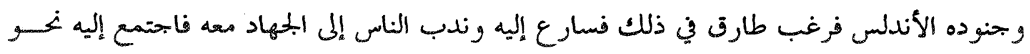

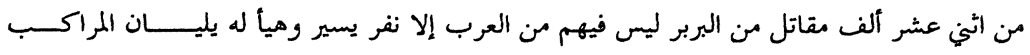

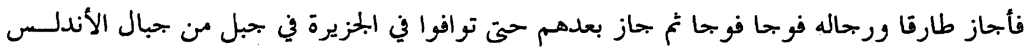

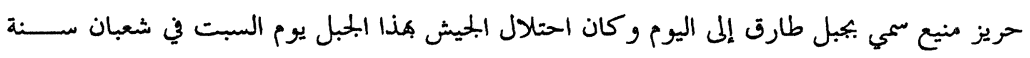

$$
\begin{aligned}
& \text { اثنين وتسعين. } \\
& \text { [2] فلما بلغ لذريق حلول طارق الأندلس حشد أهل مملكته وخرج من قصر قرطبـــة إلى }
\end{aligned}
$$

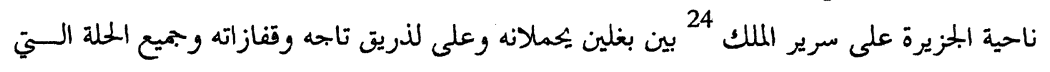

$$
\begin{aligned}
& \text { كانت الملوك تلبسها قبله والحشود تتوافن حتى نزل وادي لكة من كورة شذونة وقدم على ميمنتسـ }
\end{aligned}
$$

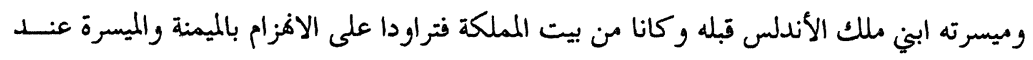

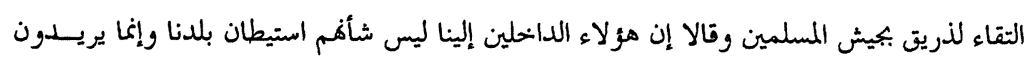

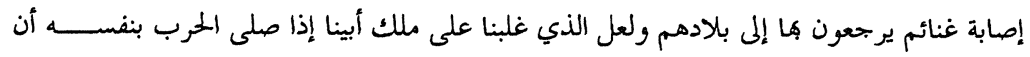

$$
\begin{aligned}
& \text { يهلك ويرجع إلينا ملكنا. }
\end{aligned}
$$

\footnotetext{
${ }^{23}$ El pasaje se extiende desde la p. 133 hasta la 152 . Hemos respetado el texto editado, siendo nuestra única intervención la supresión de las citas de otros autores, que hemos indicado mediante tres puntos entre corchetes.

${ }^{24}$ Añade en nota (p. 169): وقوله "على سرير الملك", قال غيره: وكان مكللا بالدر والياتوت.
} 


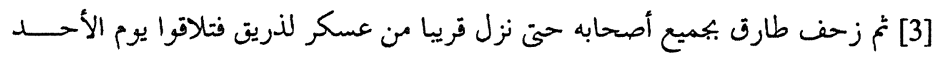

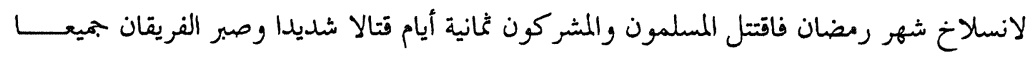

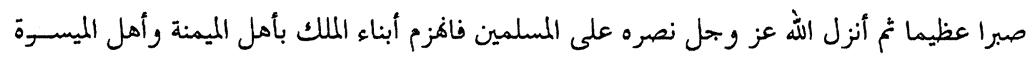

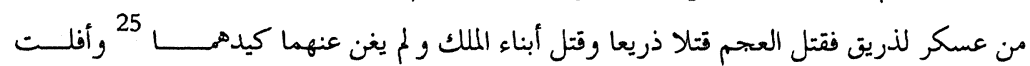

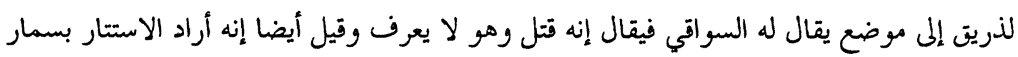

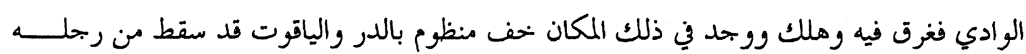

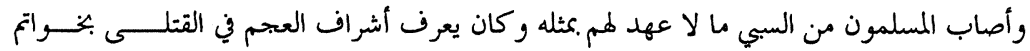

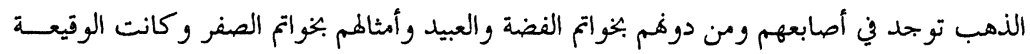

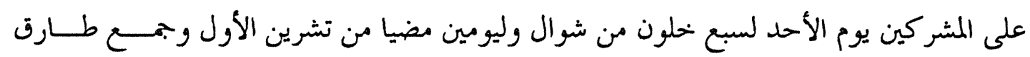

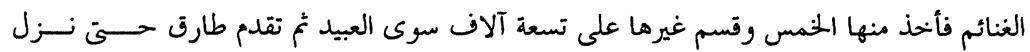
بأهل مدينة شذونة.

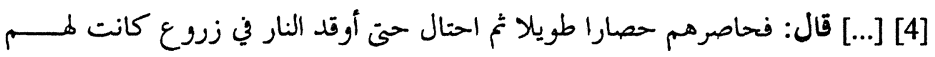

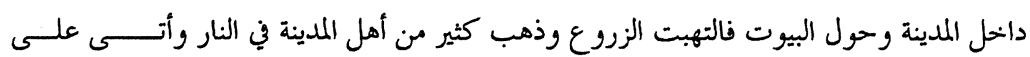
سائرهم القتل ثم تقدم إلى كورة مورور.

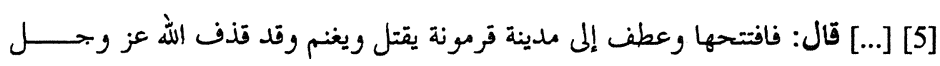

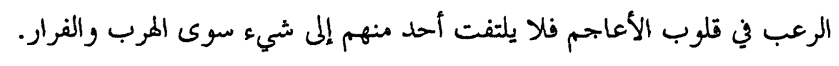

[6] [...] قال: ثم تقدم طارق إلى إشبيلية.

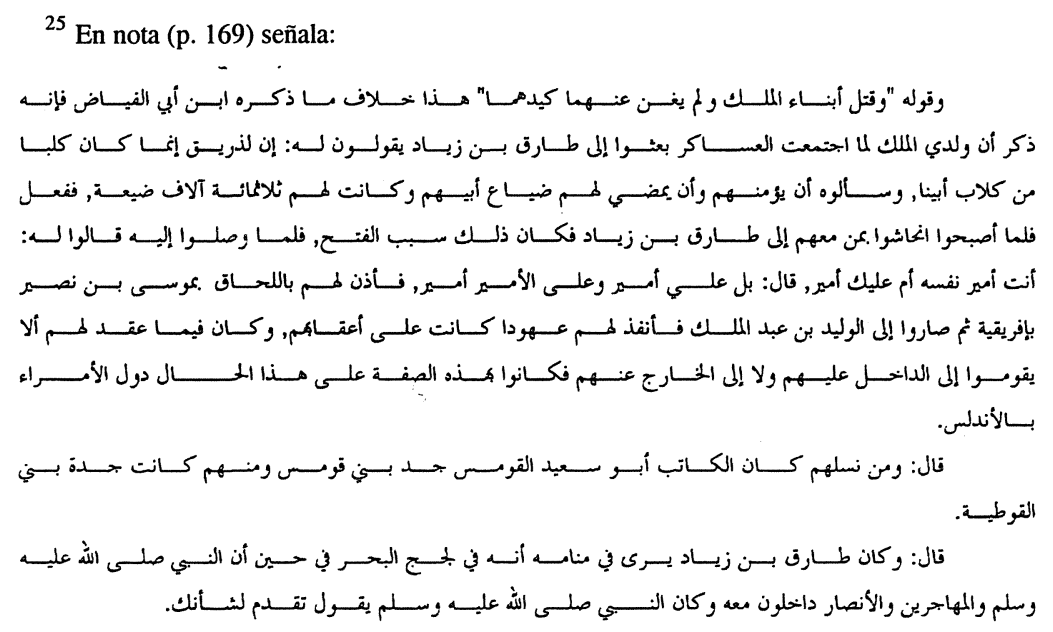


[7] [...] قال: فصالحها أهلها على إعطاء المزية وشرط عليهم إخراب غربي القصــــــ تقدم إلى أستجة فمر بعين وشرب منها فهي تعرف بالنسبة إليه ونزل بولمة أستحة.

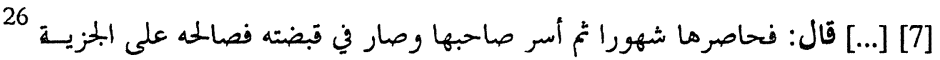
وأطلق سبيله ثُ أقبل طارق إلى قرطبة. [9] [...] قال: فلما صار قرييا منها بعث خيلا فكمنت في غيطة أرز كانت بشقندة فمسر

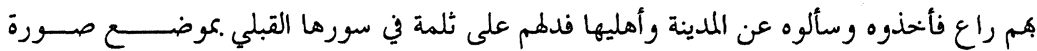

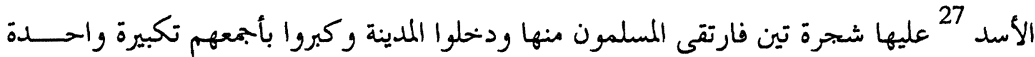

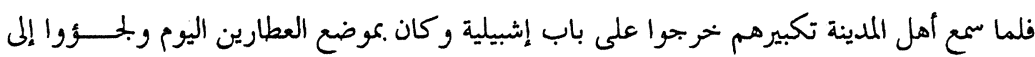

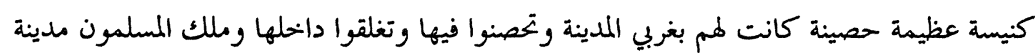

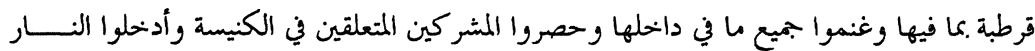

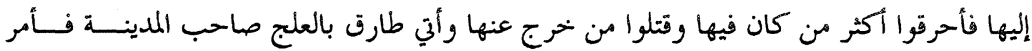
بضرب عنقه.

\section{[....] قال في مختصر تاريخ الطبري رمهه الله:}

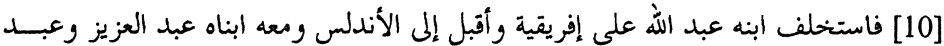

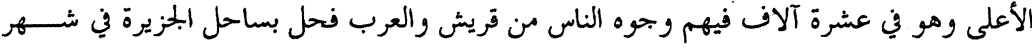

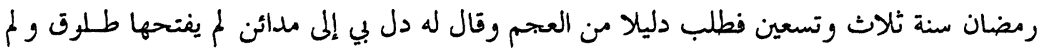

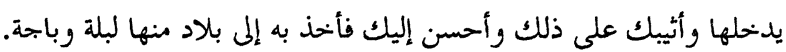

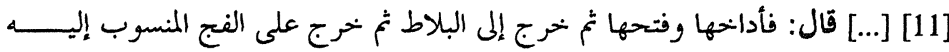

$$
\text { وهو المعروف بفج موسى. }
$$

\footnotetext{
${ }^{26}$ En nota hallamos:

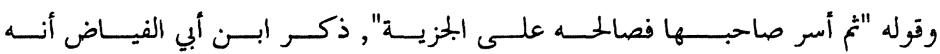

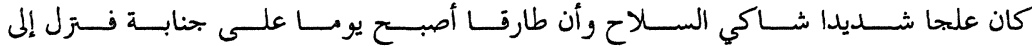

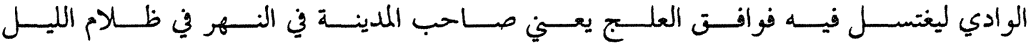

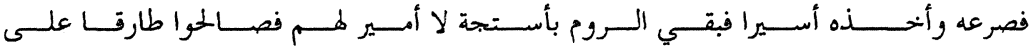
الجزيـة.

27 Añade en nota (p. 174): وقوله ".موضع صورة الأسد", قال ابن أبي الفياض: دله على ثلمة كانت في السور في برج الأسد
} 


$$
\begin{aligned}
& \text { [12] قال: فانقطع إليه أهل ذلك الموضع فأقرهم على حالمم وسموا موالي موسى ثم تقـــدم }
\end{aligned}
$$

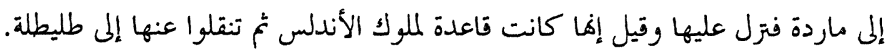

$$
\begin{aligned}
& \text { [13] [...] قال: فلازمها وحاصر أهلها حتى صالحوه على الجزية ف28. } \\
& \text { [14] قال: وكان طارق قد قدم طليطلة فافتتحها وغنمها. } \\
& \text { [15] [...] قال: وأصاب فيها مائدة منظومة بالدرر والياقوت والزبرجد وهي التي يزعـــم }
\end{aligned}
$$

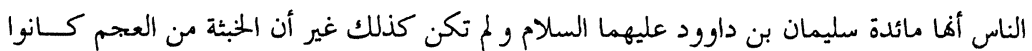

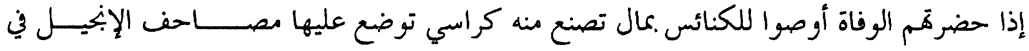

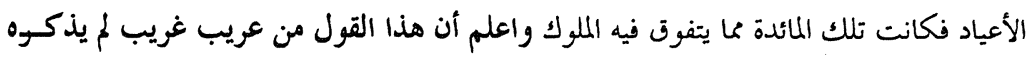

$$
\begin{aligned}
& \text { فيما علمت غيره. }
\end{aligned}
$$

$$
\text { [16] [...] قال: فلما اتصل .بموسى بن نصير ما ازداد طارق من الفتح مضى من مـــــاردة }
$$

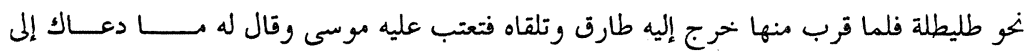

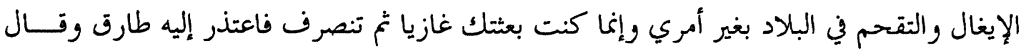

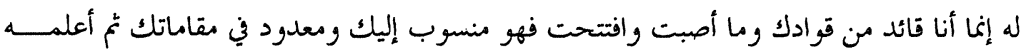

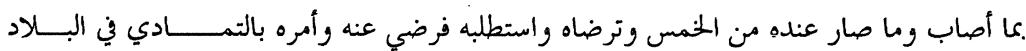

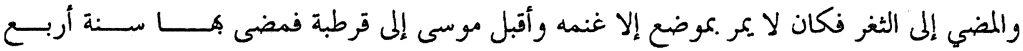
وتسعين.

$$
\text { [17] قال: : وروي أن موسى لما دخل الأندلس سنة ثلاث وتسعين ضحسـى بطليطلـــة ثم }
$$

$$
\text { تقدم إلى سرقسطة. }
$$

${ }^{28}$ Esta frase se refiere, según Ibn al-Šabbāt, a Mérida, a pesar de que, por el contexto, parece que se habla de Toledo. No debía estar muy clara la redacción que dio a este pasaje 'Arīb, porque en Fath hallamos esas palabras, "la cercó hasta que sus habitantes pactaron el pago del tributo", claramente referidas a Toledo, mientras que la Rihla, tal vez dándose cuenta de que algo no cuadraba, simplemente las omite. A pesar de las dudas que nos puede plantear la versión conservada por Ibn al-Šabbāt, nos parece fuera de toda cuestión que el relato de 'Arīb describía los acontecimientos de la siguiente manera: Mūsà conquista Mérida por rendición de sus habitantes y se dirige hacia Toledo, que ya había sido tomada por Țāriq, quien había encontrado allí la "Mesa" de Salomón - que en realidad no era tal mesa sino un atril-. Al saber de la llegada de Mūsà,Ṭāriq sale a su encuentro y se reúne con él en las afueras de Toledo. El testimonio de Fath-Rihlala, por tanto, no es válido, puesto que su afirmación de que fue Mūsà quien conquistó Toledo procede evidentemente de una mala interpretación de su fuente, probablemente no muy clara en ese pasaje. 


$$
\begin{aligned}
& \text { [18] [...] قال: وانصرف أي موسى قافلا فضحى بقرطبة سنة أربع وتسعين ولما اتصـل }
\end{aligned}
$$

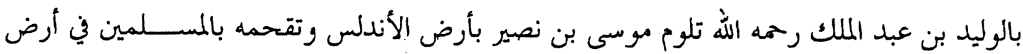

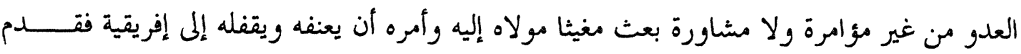

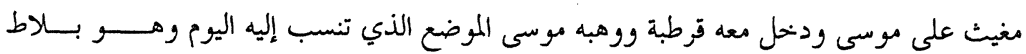

$$
\begin{aligned}
& \text { مغيث بجميع أرضه وزيتونه وغزا مغيث مع موسى بالجيش إلى جليقية. } \\
& \text { [19] واستبطأ الوليد رحمه الله قدوم موسى فبعث رسولا يعرف بأبي نصر فتو كل بموسبىى } \\
& \text { واندفع به من مدينة لك بجليقية وخرج من الفج المعروف بفج موسى ووفاه طارق بالطريق ومضيا } \\
& \text { جميعا معهما مغيث وأبو نصر ومن أراد أن يرجع من الناس إلى المشرق واستخلف موسن موسى بن بن نصير } \\
& \text { على الأندلس ابنه عبد العزيز وشخص موسى راجعا إلى إفريقية وكان قدوم موسى بن نصير على } \\
& \text { الوليد بن عبد الملك سنة ست وتسعين وحمل طارق بما حمل من الغنائم والأموال والمائدة. } \\
& \text { واعلم أن هذا ما رأيت إيراده مما في مختصر تاريخ الطبري مع ما أضفت إليه من غيره }
\end{aligned}
$$

Como ya habíamos adelantado antes, contamos con otras dos obras que reproducen un texto muy semejante al de Ibn al-Šabbāt: el anónimo Fath alAndalus y la Rihlat al-wazìr de al-Gassānī, las cuales derivan claramente de una fuente común, donde hallarían los párrafos provenientes de 'Arīb que ambas copian sin mencionarlo en ningún momento. El parentesco entre la versión de Ibn al-Šabbạt y la de Fath-Rihla es muy estrecho, hasta el punto de que no deja lugar a dudas de que nos hallamos ante un texto derivado del de 'Arīb; pero, mientras en el caso del autor de la Silat al-simt parece absolutamente fuera de toda sospecha que tuvo en sus manos un ejemplar del Mujtasar Ta'rīj al-Tabarī, la pareja Fath-Rihla recibe los pasajes que nos ocupan a través de al menos una fuente intermedia (probablemente la cadena tenga más eslabones), de modo que no podemos esperar encontrarnos con la misma fidelidad a su modelo que hallamos en Ibn al-Šabbạt. A pesar de ello, no son muchas ni muy importantes las divergencias, que, por otra parte, son debidas en su mayor parte a la fuente intermedia y no al autor del Fath ni al visir al-Gassānī, cuyos textos están tan próximos entre sí que se comprueba que ambos están siguiendo muy de cerca a su modelo y que no han introducido por su cuenta modificaciones destacables.

El Fath al-Andalus reproduce casi en su totalidad este relato de la conquista: de la primera parte, la dedicada a describir el recorrido de Ṭāriq, sólo falta el primer parágrafo de 'Arib (A, 1) mientras que A, 4 se halla muy resumido en Fath. (F I, 15). El pasaje en cuestión abarca desde F I, 12 hasta F I, 16 y las únicas diferencias reseñables que hallamos son debidas a la interpolación en el Fath de 
breves noticias tomadas de otras fuentes, como la indicación de que Rodrigo, cuando tiene conocimiento de la invasión, se hallaba combatiendo contra los vascones ${ }^{29}$ o la mención de los nombres de los dos hijos de Witiza que traicionaron a su rey $^{30}$. Desde F I, 17 hasta F I, 23 el Fath nos ofrece un testimonio diferente del de 'Arīb, tomado de "otros relatos" y de 'Abd al-Malik b. Habib, aunque se trata en realidad de un resumen de la versión de la conquista que estudiamos en nuestro trabajo anterior y que atribuimos a al-Rāzī. Esta interpolación en medio del pasaje tomado de 'Arīb se hallaba ya en la fuente común del Fath y de la Rihla, pues es justamente a partir de este punto (exactamente en F I, 21) cuando la obra del embajador marroquí comienza su relato de la conquista, idéntico al del Fath tanto cuando éste se aproxima a la narración de al-Rāzī como cuando vuelve a asemejarse a la de 'Arīb.

En efecto, a partir de F I, 23 encontramos de nuevo un texto paralelo al de Ibn al-Šabbāt, que sigue en el parágrafo siguiente y, más adelante en F I, 35 y, parcialmente, en F I, 42. En medio de estas citas desperdigadas, el compilador del Fath y al-Gassānī, siempre al unísono, vuelven a introducir préstamos tomados a Ibn Habīb a través de al-Rāzī.

${ }^{29}$ Este dato lo hallamos ya en el Muqtabis de Ibn Ḥayyān (según testimonio de al-Maqqarī, Naf̣̆ $a l-t i b$, ed. I. 'Abbās, Beirut, 1968, I, 231-232) en una narración de los acontecimientos que se aparta tanto de la que estamos viendo aquí como de la de Aḥmad al-Rāzī (Ibn 'Id dārī, al-Bayān al-mugrib, ed. Colin y Lévi-Provençal, Leiden, 1948-51, II, 8). De acuerdo con este último, Rodrigo envía varios ejércitos contra los musulmanes - uno de ellos mandado por su sobrino Banŷ— que son derrotados uno tras otro; finalmente acude él mismo y muere en la batalla del Guadalete. Las mismas noticias hallamos en la Crónica del moro Rasis (a través de lo que aparece en la Crónica de 1344, ed. Catalán y De Andrés, Madrid, 1971, 125-134). Para Ibn Ḥayyān, sin embargo, Rodrigo se entera de la entrada de los musulmanes mientras se halla combatiendo contra los vascones y se dirige con un gran ejército contra los invasores; al tener noticia de ello, Țâriq pide refuerzos a Mūsà y éste le envía cinco mil hombres, con los que derrota a Rodrigo. Esta versión reproducida por Ibn H̦ayyān (que no sería la única que incluiría en el Muqtabis, pues es muy probable que también citase las de al-Rāzĩ y 'Arīb) la volvemos a encontrar en otras obras como Ajbār maŷmü $a$ (ed. E. Lafuente Alcántara, Madrid, 1867, 7-9), alKitab al-jazä inü (Nafh, I, 255-259), Ibn al-A Ā̄r (Kämil, ed. C. J. Tornberg, Leiden, 1870, IV, 562), al-

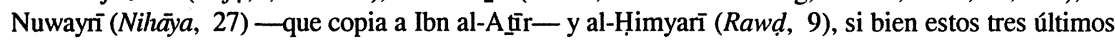
autores ofrecen unos textos muy resumidos, en los que no se identifica a los enemigos contra los que estaba luchando Rodrigo.

El relato del Imãma (II, 60) señala también que Rodrigo se hallaba combatiendo a los vascones, pero todo ese pasaje lo ha tomado de Ibn H̦abỉb (137), quien no especifica quiénes eran el objetivo de la campaña del rey godo. También deriva de Ibn Habỉb la versión de Ibn Jallikān (Wafayät al-a'yān, ed. I. 'Abbās, Beirut, 1968, V, 321, seguido por Nafh̆, I, 240), quien tampoco habla de los vascones. Se trata, por tanto de una interpolación del autor del Imáma, tomada tal vez de la misma fuente en la que bebió Ibn Hayyān.

${ }^{30}$ Aparecen con sus nombres también en Ajbār maŷmū'a (8) y Raw ḍ (10), en pasajes semejantes por su contenido, pero textualmente distintos a los de Ibn al-Šabbăt y Fath. Este es un dato que, en realidad, no sería imposible que apareciera en el texto original de 'Arīb y que Ibn al-Šabbăt lo hubiera omitido, tal y como ocurre en la cita que al-Maqqarī hace de al-Kitäb al-Jazä'ini (Nafh, I, 257), íntimamente emparentado, como es habitual, con los Ajbār maŷmü"a y que, sin embargo, omite los nombres de los hijos de Witiza en contra de lo que hacen los Ajbarr. 
En este capítulo, el dedicado al itinerario de Mūsà b. Nușayr, la confrontación entre Ibn al-Šabbặt y Fath-Rihla se hace más difícil porque la versión de estos últimos está muy interpolada, pues no sólo alternan fragmentos de 'Arỉ con otros de al-Rāzī, sino que dentro de los párrafos derivados de 'Arīb introducen frases no originales. Sin embargo, teniendo en cuenta que desde un primer momento hemos aceptado como irremediable el hecho de que la versión de Fath-Rihla sea menos fiel a su modelo que la de Ibn al-Šabbăt, no deben preocuparnos estas alteraciones, ya que la única utilidad de Fath-Rihla para nuestro propósito actual es la de servir de punto de referencia para comprobar la exactitud de la versión de Ibn al-Šabbăt o, mejor dicho, para cerciorarnos de que es completa, puesto que, por las razones anteriormente expuestas, damos por sentado que el autor tunecino sólo se diferencia de sus fuentes por la omisión de alguna frase en ocasiones muy contadas.

Debemos fijarnos, por tanto, en las frases y noticias que hallamos en FathRihlla y que faltan en Ibn al-Šabbăt, a fin de detectar posibles omisiones en el texto de éste.

La mayoría de los pasajes de Fath-Rihla que faltan en la Șila son claramente interpolaciones tomadas de fuente distinta a 'Arïb; un buen ejemplo puede ser la noticia de que Țâriq arrancó una de las patas de la "Mesa» de Salomón para tener una prueba de que fue él quien la encontró. Es difícil aceptar que 'Arīb incluyese en su crónica esta información, sobre todo si tenemos en cuenta que, en su opinión, «lo que la gente cree que era la Mesa de Salomón" no era tal, sino un atril para los Evangelios. La fuente común a Fath y Rihla modificó el texto proveniente de "Arib para poder introducir la sabrosa historia de la pata arrancada por Țāriq, pero su intervención no fue lo acertada que él hubiera deseado, pues mantuvo las primeras palabras de la frase de "Arib ("pero no es así") en la que éste muestra su escepticismo sobre la autenticidad de la "Mesa” de Salomón. La Rihla mantuvo esa frase delatora, pero el compilador del Fath debió de darse cuenta y la suprimió.

Pero si esa interpolación es indudable, no podemos estar tan seguros en el otro caso más llamativo: las discrepancias a la hora de describir las etapas del itinerario de Mūsà, desde que busca guías que lo conduzcan por una ruta distinta a la de Țāriq hasta que llega a Toledo. Los tres textos son:

Șilat al-simt (p. 145)

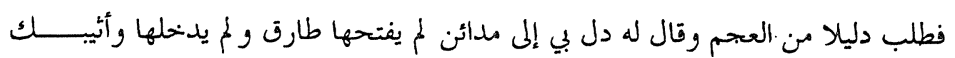

$$
\begin{aligned}
& \text { على ذلك وأحسن إليك. } \\
& \text { فأخذ به إلى بلاد منها لبلة وباجة ـ قال: فأداخها وفتحها ثم خرج إلى البلاط. } \\
& \text { ثم خرج على الفج المنسوب إليه وهو المعروف بفج موسى. }
\end{aligned}
$$


Fath al-Andalus (§ 24, p. 24)

$$
\begin{aligned}
& \text { فطلب دليلا من العجم يدل به إلى المدن التي لم يفتحها طارق ووعده بالجزاء على ذلك. }
\end{aligned}
$$

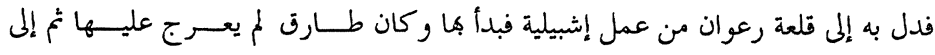

$$
\begin{aligned}
& \text { أكشونبة على شاطىء البحر فافتتحهما وغيرهما سلما وحربا. } \\
& \text { ثم خر ج من هنالك على الفج المنسوب إليه. }
\end{aligned}
$$

Rihlat al-wazīr (p. 108)

فطلب دليلا من العجم يدل به إلى المدن التي لم يفتحها طارق ووعده على ذلك بالمبـــــاء

$$
\begin{aligned}
& \text { والجزاء. } \\
& \text { فذل به إلى قلعة زعواق من عمل إشبيلية فبدأ هما و كان طارق لمُ بعرج عليــها ثم صـار } \\
& \text { منها إلى لبلة ثم إلى باجة ثم إلى أكشونبة على سيف البحر فافتتحها أجمع سلما. } \\
& \text { ثم خرج من ذلك القطر على الفج المنسوب إليه من حوز القنت. }
\end{aligned}
$$

Como se puede apreciar, de los tres párrafos en que hemos dividido el pasaje, el primero y el tercero son casi idénticos en las tres fuentes, siendo la única diferencia que la Rihla especifica que el Faŷy Müsà está en la región de al-Qant.

Sin embargo en el segundo párrafo las diferencias son destacables: Ibn alŠabbật hace pasar a Mūsà por Niebla, Beja y al-Balät, el Fath, por Qal'at Ra'wān y Ossonoba, y la Rihla, por Qal'at Za'wāq, Niebla, Beja y Ossonoba. Parece evidente que el compilador del Fath omitió la mención de Niebla y Beja, que se hallaban en su fuente, tal y como demuestra su presencia en la Rihla, por lo demás idéntica al Fath en todo lo demás.

La cuestión que se nos plantea es explicar la ausencia en Ibn al-Šabbạ̄t de dos etapas del recorrido, una antes de Niebla y Beja, Qal'at $R a$ 'wān o Za'wāq, el Ragwāl que Hernández Jiménez identifica con Alcalá del Río ${ }^{31}$, y otra después, Ossonoba. Si todos los casos anteriores en los que hallábamos noticias más extensas o detalladas en Fath-Rihla podían ser explicados por interpolaciones introducidas por la fuente común a estas dos obras, en esta ocasión hay datos que nos obligan a prestar un poco de atención.

\footnotetext{
${ }^{31}$ «Ragwāl y el itinerario de Mūsà, de Algeciras a Mérida», Al-Andalus XXVI (1961), 43-153.
} 
Disponemos de otras dos fuentes que reproducen este pasaje de acuerdo con la versión de 'Arīb; es algo sorprendente, ya que el relato principal que siguen esas dos obras no es el de 'Arib, pero lo cierto es que en este punto abandonan su fuente habitual para incluir un párrafo inequívocamente emparentado con el que acabamos de analizar. Las dos crónicas en cuestión son el anónimo Dikr biläd alAndalus y el texto atribuido a Ibn Abī l-Fayyāḍ; el primero de ellos nos ofrece una descripción de la conquista muy deslavazada y resumida, en la que es difícil precisar sus fuentes, mientras que Ibn Abī l-Fayyāḍ sigue en general muy de cerca la narración de Ahmad al-Rāzî̉ ${ }^{-32}$ y de hecho regresa a ella después de haber intercalado este párrafo de 'Arīb. Los dos textos rezan:

Dikr (p. 99)

$$
\begin{aligned}
& \text { فظلب دليلا من العجم يدله على بلاد لم يدخلها طارق. }
\end{aligned}
$$

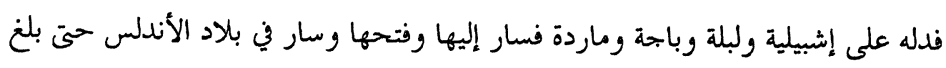

$$
\begin{aligned}
& \text { إلى قلعة عوان ثم إلى البلاط. }
\end{aligned}
$$

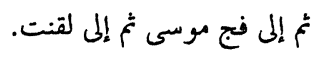

Ibn Abī l-Fayyāụ (p. 46)

$$
\begin{aligned}
& \text { فطلب دليلا من العجم يدله على بلد أن لم يدخلها طارق بن زياد. } \\
& \text { فدله على لبلة وباجة وخشوثية وماردة. }
\end{aligned}
$$

Vemos que el $D i k r$ menciona, por este orden, Sevilla, Niebla, Beja, Mérida, Qal'at 'Awwān, al-Balāt y Laqant, mientras que Ibn Abī l-Fayyāọ se limita a nombrar Niebla, Beja, Ossonoba y Mérida. El testimonio conjunto de estas dos

${ }^{32}$ Como es habitual a lo largo de todo el pasaje, la versión de al-Rāzī se demuestra cercana a la de 'Arīb en cuanto al fondo, pero distinta en la forma. En efecto, al-Rāzī señala también que fueron sus aliados cristianos los que le indicaron el camino a seguir para no coincidir con el de Tâariq. Sin embargo, la frase, reproducida casi literalmente por distintas fuentes, es en al-Rāzī (versión de Ajbär maŷmü ä, p. 15):

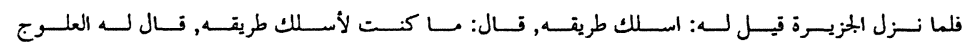

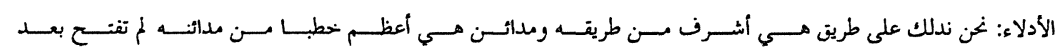

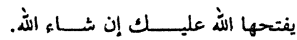


obras y del Fath y la Rihla nos podría hacer pensar que Ibn al-Šabbāt ha omitido alguna de las etapas del recorrido de Mūsà, como Ragwäl y Ossonoba, así como la precisión de que el Faŷŷ Mūsà se halla en el alfoz de Laqant (Fuente de Cantos). Pero en historiografía cuenta más la calidad que la cantidad y, de acuerdo con eso, debemos dar preferencia a Ibn al-Šabbāt, no sólo porque su fidelidad a las fuentes está fuera de toda sospecha, sino, sobre todo, porque utiliza de primera mano el texto de 'Arỉb, al contrario que Ibn Abī l-Fayyāạ, Dikr, Fath y Rihla, que no lo conocieron de manera directa. Fath y Rihla, como ya se ha señalado en repetidas ocasiones, derivan de una misma fuente; fuente que recogía, probablemente tampoco de primera mano, textos derivados tanto de 'Arīb como de alRāzī. Del $\underline{D} i k r$, por su parte, difícilmente podría decirse que utilice materiales originales y, aunque no podemos demostrar que conociera la fuente común a Fath y Rihla, no es una posibilidad descabellada, teniendo en cuenta que hay pasajes en el Dikr estrechamente emparentados con otros de la Rihla $a^{33}$. Ibn Abī l-Fayyāọ, por último, es un historiador no muy tardío, del siglo $\mathrm{XI}^{34}$, y de cierto prestigio, pero lo cierto es que no tuvo ante sus ojos la obra de 'Arīb, al menos a la vista de lo que podemos deducir por lo que se ha conservado de su obra y de las citas en autores posteriores, donde se aprecian claras influencias de Aḥmad al-Rāzī y de Ibn al-Qūtiyya ${ }^{35}$.

Aunque no es imposible que el texto original de 'Arīb incluyese las menciones de Qal'at Ragwāl y Ossonoba en el itinerario de Mūsà, en principio creemos preferible el testimonio inmediato y fiel de Ibn al-Šabbāt, de modo que habría que considerar la presencia de esos topónimos en otras fuentes como interpolaciones posteriores cuyo origen desconocemos. Únicamente un mínimo dato, la ubicación del Faŷy Mūsà en el alfoz de Laqant, registrado por la Rihla y del que se hallan vestigios en el $\underline{D} i k r$, tiene una procedencia conocida, Ibn alQūtiyya, quien señala ${ }^{36}$ :

\footnotetext{
${ }^{33}$ Referidos a la descripción de Córdoba y, en especial, de su mezquita (compárense, por ejemplo, Rihla, 19 y Dikr biläd al-Andalus, ed. L. Molina, Madrid, 1983, I, 115-116).

${ }^{34}$ Álvarez de Morales, C., "Aproximación a la figura de Ibn Abī l-Fayyāḍ,, 30-33.

${ }^{35}$ De al-Rāzī deriva, como antes dijimos, su descripción de la conquista («Un relato de la conquistan, 42). La influencia de Ibn al-Qūtiyya es también evidente, tanto en los pasajes que conocemos a través de citas atribuidas a Ibn Abī l-Fayyāạ en otras fuentes como en los fragmentos conservados de un texto que se suele considerar salido de su pluma. Ejemplo de lo primero es el párrafo que Ibn al-Šabbāt dice tomar de él (Șila, 169-170) al referir las negociaciones entre los hijos de Witiza y Țāriq, idéntico al que hallamos en Ibn al-Qūtiyya (Ta'rū Iftităh al-Andalus, Madrid, 1926, 3-4), reproducido también en su integridad por al-Maqqarī (Nafh, I, 265-268, probablemente a través de Ibn Hayyān). En cuanto al texto que se le atribuye, compárense los relatos del regreso de los conquistadores a Oriente ( «Ibn Abī l-Fayyādn, 48-49; Iffitađln, 10-11), prácticamente iguales, con la salvedad de que Ibn Abī l-Fayyạ̣ intercala en medio de la narración un párrafo que incluye algunas frases tomadas de otras fuentes, como la discusión entre Mūsà y Țāriq sobre quién había conseguido la "Mesa de Salomón", que deriva manifiestamente de Ibn 'Abd al-Ḥakam (Futuhl, 211).

${ }^{36}$ Ta'rij Iftităh al-Andalus, 9 .
} 


$$
\text { ثم قصد من إشبيلية إلى لقنت إلى الموضع المعروف بفج موسى في أول لقنت إلى ماردة }
$$

Como conclusión a todo lo que hemos venido exponiendo, parece claro que el texto que nos ha transmitido Ibn al-Šabbāt es fiel reflejo del que se debía incluir en el Mujtașar Ta'rīj al-Ṭabarī de 'Arīb. La versión de la conquista que nos ofrece este cronista cordobés es semejante en líneas generales a la de Ahmad alRāzī, más difundida entre los historiadores posteriores, pero presenta diferencias en detalles importantes, como es el itinerario seguido por los conquistadores, además de una redacción totalmente original, por lo que no hallamos paralelos textuales entre las dos obras.

Con los datos aportados por este trabajo y con los obtenidos en el anterior, disponemos ya de los textos depurados de dos de las versiones más fiables sobre la conquista musulmana de la península Ibérica. Junto con las que se nos han conservado en su redacción original (Ibn 'Abd al-Ḥakam, Ibn Ḥabīb, Ibn alQütiyya) representan un alto porcentaje del material documental base del que vivió a lo largo de los siglos la historiografía árabe para elaborar sus historias de la conquista. Conociendo los textos primordiales no deberá sernos difícil diseccionar las informaciones contenidas en las crónicas que nos han llegado a fin de precisar el origen exacto de cada una de sus frases; esto nos permitirá rectificar errores de transmisión, identificar falsificaciones y devolver a su estado original párrafos alterados por mezclas e interpolaciones.

\section{RESUMEN}

Reconstrucción de la descripción que de la conquista musulmana de la Península Ibérica hizo el cronista cordobés del siglo $\mathrm{X}$ 'Arīb $\mathrm{b}$. Sa'îd. Aunque no se nos ha conservado el relato, las citas de que él hacen autores posteriores, especialmente Ibn alŠabbặt (s. XIII), nos permiten conocer casi en su literalidad el texto de 'Arīb. Esta versión de la conquista se asemeja en sus líneas generales a la de al-Rāzì, estudiada en un reciente trabajo en esta misma revista, aunque las diferencias en los detalles son lo suficientemente notables como para considerarla una versión totalmente independiente.

\section{ABSTRACT}

In this article, the description by 'Arib b. Sa'id (10th century) of the Muslim conquest of the Iberian Peninsula is reconstructed on the basis of quotations by later authors, especially Ibn al-Šabbạt (13th century). Although 'Arīb's text itself is lost, these 
quotations provide a nearly complete transcription of his description of the conquest. In general, 'Arīb's version is similar to that of al-Rāzī, analyzed in an article recently published in this journal. But the differences between the two narratives are of enough significance to make us consider 'Arīb's text completely independent from al-Rāzī's. 